\title{
Antiemetic efficacy of capsicum plaster on acupuncture points in patients undergoing thyroid operation
}

\author{
Min Seok Koo ${ }^{1}$, Kyo Sang Kim², Hee-Jong Lee ${ }^{2}$, Ji Seon Jeong ${ }^{2}$, and Jung-Won Lee ${ }^{1}$ \\ Department of Anesthesiology and Pain Medicine, ${ }^{1}$ National Medical Center, ${ }^{2}$ Hanyang University Hospital, Seoul, Korea
}

Background: Postoperative nausea and vomiting (PONV) occurs in up to 63-84\% of patients after thyroid surgery. This study aims to assess the effects of using a capsicum plaster to reduce PONV after thyroid surgery at either the Chinese acupuncture point (acupoint) Pericardium 6 (P6) or Korean hand acupuncture point K-D2.

Methods: One-hundred eighty-four patients who underwent thyroid surgery were randomized in four groups $(\mathrm{n}=46$ each): control group = inactive tape at P6 acupoints and on both shoulders as a nonacupoint; P6 group = capsicum plaster at $\mathrm{P} 6$ points and inactive tape on both shoulders; K-D2 group = capsicum plaster at K-D2 acupoints and inactive tape on both shoulders; Sham group = capsicum plaster on both shoulders and inactive tape at P6 acupoints. The capsicum plaster was applied before the induction of anesthesia and removed at $8 \mathrm{hr}$ after surgery.

Results: The incidence and severity of nausea and vomiting and the need for rescue antiemetics were decreased in the patients in the P6 and K-D2 groups compared to the patients in the control and sham groups $(\mathrm{P}<0.001)$. The patients in the P6 and K-D2 groups also reported that they were more satisfied $(\mathrm{P}<0.05)$.

Conclusions: We conclude that the capsicum plaster at the P6 and K-D2 acupoint was a promising antiemetic method for the patients undergoing thyroid surgery. (Korean J Anesthesiol 2013; 65: 539-543)

Key Words: Acupuncture, Capsaicin, Nausea and vomiting, Thyroid surgery.

\section{Introduction}

Postoperative nausea and vomiting (PONV) is unpleasant and is a frequent adverse event associated with anesthesia and surgery. Avoiding PONV is important to patients, more than postoperative analgesia [1]. As such, many patients are willing to pay on average $100 €$ postoperatively for effective pharmacologic antiemetics, as reported in a study done in Europe [2]. The reported incidence of PONV for patients undergoing thyroid surgery is between 63 and $84 \%[3,4]$. Stimulation at the Chinese acupuncture point Pericardium 6 (P6) is described as an alternative method for preventing the development of PONV [5,6]. Acustimulation on Korean hand acupuncture points (K-K9, $\mathrm{K}-\mathrm{D} 2)$ also have been reported as antiemetic approaches after surgery $[7,8]$.

Capsicum plaster (Sinsin Capsicum Hot Round Plaster ${ }^{\circledR}$, Sin-

Received: April 24, 2013. Revised: 1st, May 27, 2013; 2nd, June 17, 2013. Accepted: June 25, 2013.

Corresponding author: Kyo Sang Kim, M.D., Ph.D., Department of Anesthesiology and Pain Medicine, Hanyang University Hospital, 17, Haengdang-dong, Sungdong-gu, Seoul 133-792, Korea. Tel: 82-2-2290-8680, Fax: 82-2-2299-0742, E-mail: kimks@hanyang.ac.kr

(c) This is an open-access article distributed under the terms of the Creative Commons Attribution Non-Commercial License (http:// creativecommons.org/licenses/by-nc/3.0/), which permits unrestricted non-commercial use, distribution, and reproduction in any medium, provided the original work is properly cited. 
sin Pharm., Seongnam, Korea), which contains $0.49 \mathrm{mg}$ methyl salicylate, $1.64 \mathrm{mg}$ powdered capsicum, and $0.16 \mathrm{mg}$ capsicum tincture on a round sheet (diameter $1.1 \mathrm{~cm}$, area $0.95 \mathrm{~cm}^{2}$ ), is a popular analgesic technique in Korea based on its economic feasibility and efficacy. Capsicum plaster has been used as an alternative to oral pain medication and antiemetics after several surgeries [8-11].

In this study, the primary endpoint was to assess the clinical use of capsicum plaster for the prevention of PONV, as measured by the prevention of emetic episodes at $24 \mathrm{hr}$ after thyroid surgery.

\section{Materials and Methods}

The study protocol was approved by our institution's ethical committee and informed consent was obtained from all patients. Patients that were ultimately included in this study $(\mathrm{n}=184)$ had an American Society of Anesthesiologists status of I-II, were between the ages of 21 and 64 years old and were scheduled for thyroid surgery between November 2012 and March 2013. Patients with at least one of the following criteria were excluded: obesity (> 130\% ideal body weight), gastro-esophageal reflux, antiemetic medications, a histamine $\mathrm{H}_{2}$-receptor antagonist or tranquilizers within $72 \mathrm{hr}$ before surgery, and any pulmonary disease.

Participants in this placebo, sham-controlled study were randomly assigned to the control group $(n=46)$, the P6 group $(\mathrm{n}=46)$, the K-D2 group ( $\mathrm{n}=46)$, or the sham group $(\mathrm{n}=46)$. After enrollment, patients were randomized to four groups by sealed envelope. In the P6 group, capsicum plaster $\left(0.95 \mathrm{~cm}^{2}\right)$ was applied at the P6 (Nei Guan) acupoint, located three finger breadths below the wrist on the both inner forearms between the tendons of the palmaris longus and the flexor carpi radialis [12] and an inactive tape $\left(0.95 \mathrm{~cm}^{2}\right)$ was taped at the deltoid region of both shoulders as a nonacupoint [11]. In the K-D2 group, capsicum plaster $\left(0.95 \mathrm{~cm}^{2}\right)$ was applied at the K-D2 acupoint, located on the lateral distal phalanx of the index finger of both forearms [8] and an inactive tape at both deltoid regions. In the control group, an inactive tape $\left(0.95 \mathrm{~cm}^{2}\right)$ was attached at the P6 acupoint of both inner forearms and at both deltoid regions. In the sham group, capsicum plaster $\left(0.95 \mathrm{~cm}^{2}\right)$ was attached on both shoulders and an inactive tape was taped at both P6 points (Fig. 1). After the capsicum plaster was taped to the above sites, a plastic adhesive covered the entire region. The patients and the investigators as well as anesthesiologists and nurses, were unaware of the patient grouping. Both capsicum plaster and placebo tape were applied for a period of $30 \mathrm{~min}$ before the induction of anesthesia and maintained for $8 \mathrm{hr}$.

No premedication was given. Monitoring before anesthetic induction consisted of automated noninvasive arterial blood pressure, continuous electrocardiogram, and oxygen saturation. All patients were connected to a bispectral index (BIS) monitor (Model A 2000, Aspect Medical Systems, Natick, MA, USA). Anesthesia was induced with $0.5 \mu \mathrm{g} / \mathrm{kg} / \mathrm{min}$ of remifentanil injected intravenously (IV) over $120 \mathrm{~s}$ followed by $2-2.5 \mathrm{mg} /$ $\mathrm{kg}$ of propofol injected by IV over $30 \mathrm{~s}$. Neuromuscular block was established with $0.6 \mathrm{mg} / \mathrm{kg}$ of rocuronium. The patients had controlled ventilation via a tracheal tube with $50 \%$ oxygen-enriched air. Anesthesia was maintained with 1-1.5 MAC of sevo-

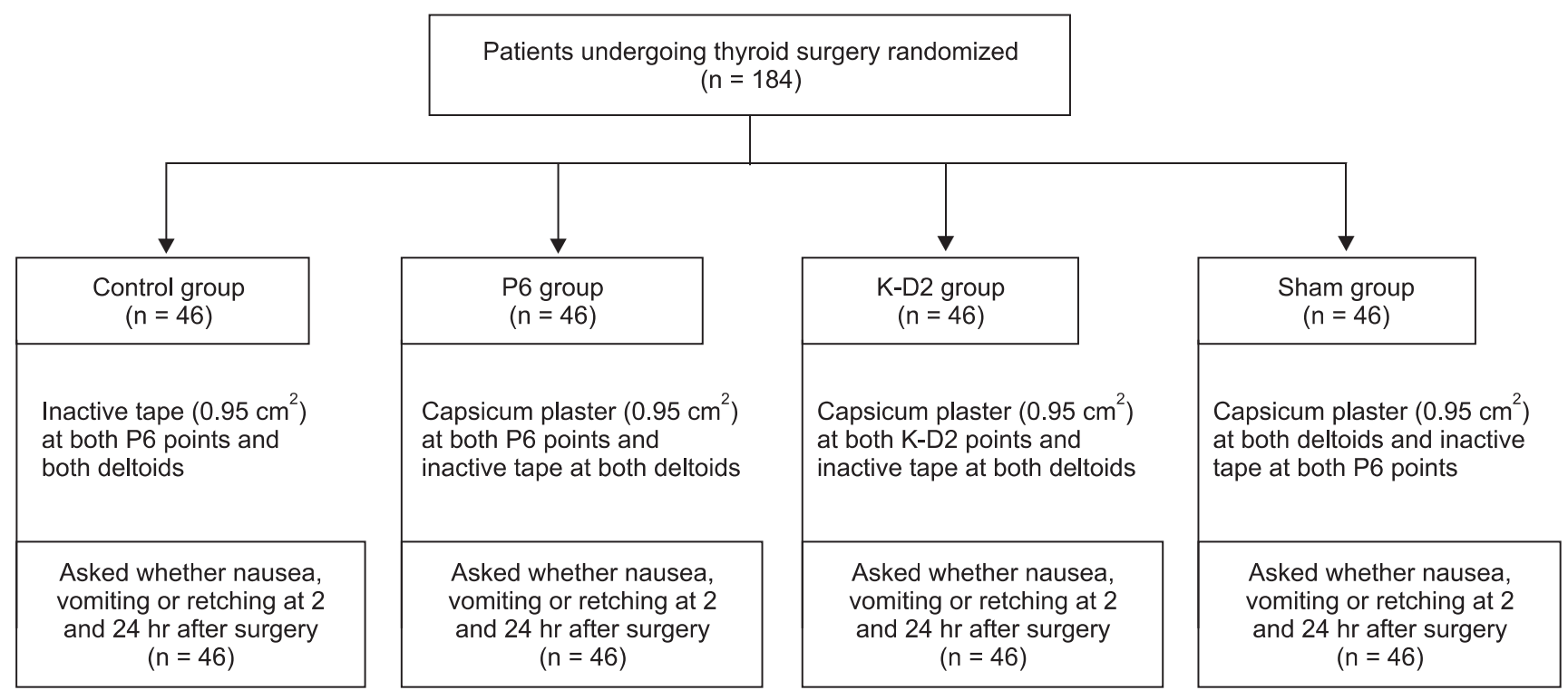

Fig. 1. Flow diagram of study participants. P6 group: capsicum plaster at the P6 and an inactive tape at the deltoid region of both shoulders, K-D2 group: capsicum plaster at the K-D2 acupoint and an inactive tape at both deltoid regions, Control group: an inactive tape at the P6 acupoint and at both deltoid regions, Sham group: capsicum plaster on both shoulders and an inactive tape at both P6 points. 
flurane in order to hold the BIS between 40 and 50. Analgesia was provided by $0.05-0.20 \mu \mathrm{g} / \mathrm{kg} / \mathrm{min}$ remifentanil during the surgery. At the end of the operation, IV glycopyrrolate $(0.4 \mathrm{mg})$ and neostigmine $(1.5 \mathrm{mg}$ ) were administered to reverse residual neuromuscular block, and the trachea was extubated.

Upon arrival at the postanesthetic care unit, $50 \mu \mathrm{g}$ fentanyl and $30 \mathrm{mg}$ ketorolac were injected into the IV by anesthesiologists to provide satisfactory analgesia. Most patients felt comfortable after this pain medication. Nausea and vomiting were evaluated from 0 to $2 \mathrm{hr}$ and from 2 to $24 \mathrm{hr}$ postoperatively by a doctor, who was blinded to group assignment. Vomiting was defined as forceful expulsion of gastric contents from the mouth. Retching was defined as an active attempt to vomit without expulsion of gastric contents. Retching was included in vomiting. Rescue antiemetics (metoclopramide $10 \mathrm{mg}$ IV) were given in each blinded observer's judgment or by patient request. The severity of nausea was assessed according to a $10 \mathrm{~cm}$ visual analogue scale (VAS) (0, none; 10, maximum). Patients' characteristics and procedure duration were recorded, as well as antiemetic and analgesic use. The patients' satisfaction was recorded $24 \mathrm{hr}$ after surgery on a $10 \mathrm{~cm}$ VAS with $10 \mathrm{~cm}$ indicating complete satisfaction.

The sample size was calculated by a power analysis. To obtain an $80 \%$ chance $(\beta=0.2)$ of finding a $50 \%$ reduction in PONV incidence (from 64 to $32 \%$ ) during the first $24 \mathrm{hr}$ after surgery with an a error of 5\%, 44 patients were required for each group [4]. Taking potential dropouts into consideration, we decided to randomize 46 patients into each group. One-way ANOVA was used to compare continuous variables. Categorical variables were analyzed using the $\chi^{2}$ test or Fisher's exact test, as appropriate. Data are presented as number and percentage, or mean \pm standard deviation (SD). SPSS software for Windows version 15.0 (SPSS Inc., Chicago, IL, USA) was used for the analysis. P values $<0.05$ were considered to indicate statistical significance.

\section{Results}

There were no dropouts among the 184 enrolled subjects (Fig. 1). The patients' characteristics, such as sex, age, weight, height, duration of anesthesia, history of PONV, history of motion sick-

Table 1. Demographic Data of Patients Treated with Capsicum Plaster

\begin{tabular}{|c|c|c|c|c|c|}
\hline & Control & P6 & $\mathrm{K}-\mathrm{D} 2$ & Sham & $\mathrm{P}$ \\
\hline $\mathrm{n}$ & 46 & 46 & 46 & 46 & \\
\hline $\mathrm{M} / \mathrm{F}$ & $14 / 32$ & $17 / 29$ & $18 / 28$ & $15 / 31$ & 0.813 \\
\hline Age (yr)(range) & $46.8 \pm 9.9(24-60)$ & $49.2 \pm 10.8(26-64)$ & $45.8 \pm 9.9(25-63)$ & $47.1 \pm 11.1(21-64)$ & 0.473 \\
\hline Weight (kg) & $61.7 \pm 11.9$ & $62.7 \pm 9.2$ & $60.6 \pm 11.4$ & $64.7 \pm 12.1$ & 0.34 \\
\hline Height $(\mathrm{cm})$ & $161.5 \pm 8.9$ & $162.3 \pm 7.5$ & $162.9 \pm 6.6$ & $159.1 \pm 8.0$ & 0.1 \\
\hline Duration of anesthesia (min) & $100.8 \pm 26.4$ & $99.2 \pm 26.9$ & $103.6 \pm 25.1$ & $102.6 \pm 22.1$ & 0.846 \\
\hline History of PONV, n (\%) & $11(24.0)$ & $13(28.2)$ & $12(26.1)$ & $10(21.7)$ & 0.896 \\
\hline History of motion sickness, $\mathrm{n}(\%)$ & $8(17.4)$ & $7(15.2)$ & $9(19.6)$ & $7(15.2)$ & 0.935 \\
\hline Nonsmoking status, $\mathrm{n}(\%)$ & $40(87.0)$ & $38(82.6)$ & $39(84.9)$ & $41(89.1)$ & 0.828 \\
\hline Intraoperative remifentanil $(\mu \mathrm{g})$ & $373.8 \pm 37.6$ & $365.1 \pm 36.2$ & $371.2 \pm 40.9$ & $354.3 \pm 34.7$ & 0.063 \\
\hline
\end{tabular}

Values are expressed as mean \pm SD or n (\%). P6 group: capsicum plaster at the P6 and an inactive tape at the deltoid region of both shoulders, K-D2 group: capsicum plaster at the K-D2 acupoint and an inactive tape at both deltoid regions, Control group: an inactive tape at the P6 acupoint and at both deltoid regions, Sham group: capsicum plaster on both shoulders and an inactive tape at both P6 points.

A

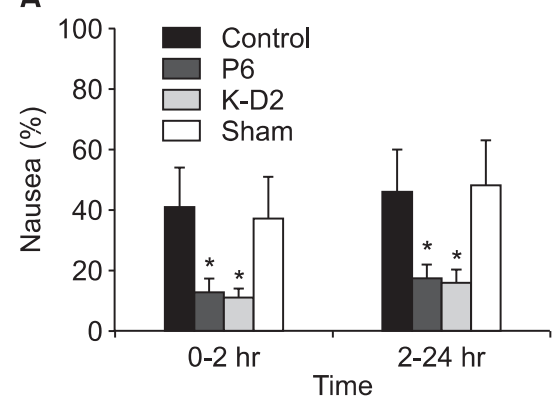

B

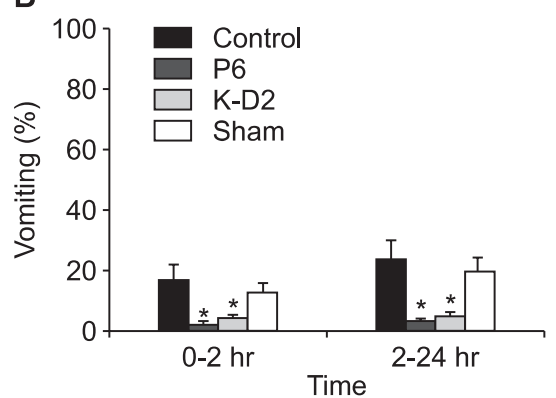

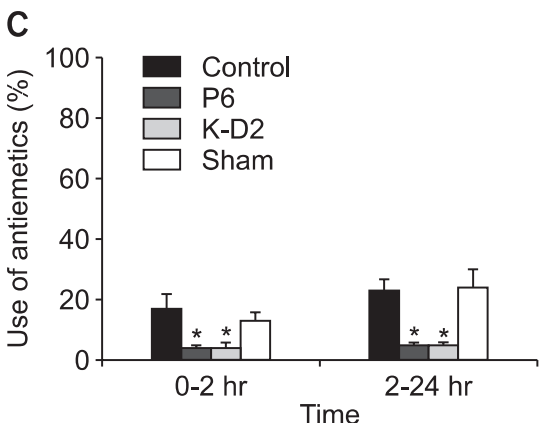

Fig. 2. Incidence of (A) nausea and (B) vomiting, and (C) the use of antiemetics in each study group during the 24 hr postoperative period. P6 group: capsicum plaster at the P6 and an inactive tape at the deltoid region of both shoulders, K-D2 group: capsicum plaster at the K-D2 acupoint and an inactive tape at both deltoid regions, Control group: an inactive tape at the P6 acupoint and at both deltoid regions, Sham group: capsicum plaster on both shoulders and an inactive tape at both P6 points. For each group, the error bar indicates the value of the upper limit of the $95 \%$ confidence interval for the percentage of patients achieving the endpoint. $* \mathrm{P}<0.001$ compared with the control and sham groups. 


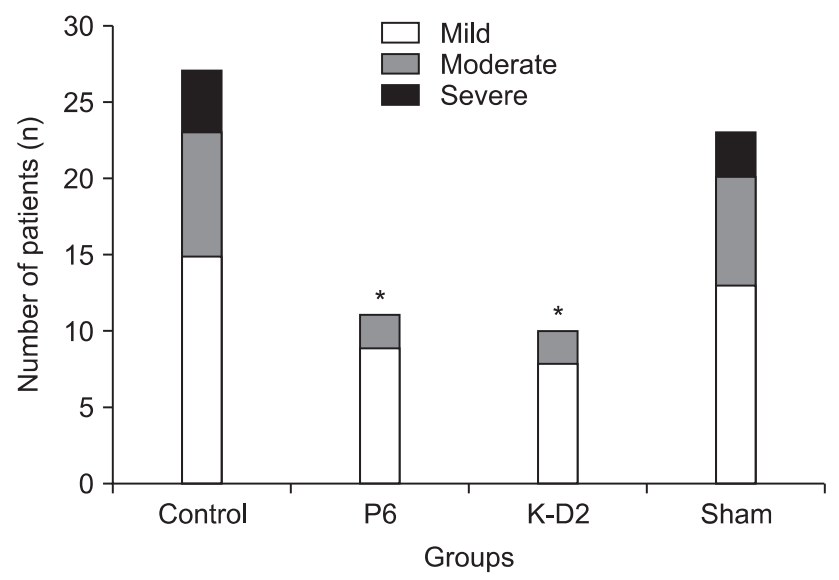

Fig. 3. Severity of nausea during the $24 \mathrm{hr}$ postoperative period. ${ }^{*} \mathrm{P}<$ 0.001 compared with the control and sham groups. P6 group: capsicum plaster at the P6 and an inactive tape at the deltoid region of both shoulders, K-D2 group: capsicum plaster at the K-D2 acupoint and an inactive tape at both deltoid regions, Control group: an inactive tape at the P6 acupoint and at both deltoid regions, Sham group: capsicum plaster on both shoulders and an inactive tape at both P6 points.

ness, nonsmoking status and intraoperative remifentanil use, were comparable between groups (Table 1). The incidence of nausea, vomiting and anti-emetics during the $24 \mathrm{hr}$ after surgery was lower in the P6 (24\%, $4 \%$ and $6 \%$, respectively) and K-D2 (22\%, 6\% and 6\%, respectively) groups compared with the control (59\%, 30\% and 30\%, respectively) and sham (50\%, 24\% and $33 \%$, respectively) groups $(\mathrm{P}<0.001)$ (Fig. 2). The severity of nausea was significantly lower in the P6 and K-D2 groups compared with the control and sham groups $(\mathrm{P}<0.001)$ (Fig. 3). Overall satisfaction scores were significantly higher in the P6 $(8.4 \pm 1.5)$ and K-D2 $(8.3 \pm 1.4)$ groups compared to the control $(7.2 \pm 1.6)$ and sham $(7.3 \pm 1.6)$ groups $(\mathrm{P}<0.05)($ Fig. 4$)$.

\section{Discussion}

We found that applying capsicum plaster at the P6 or K-D2 acupoints was more effective in lowering the incidence of nausea and vomiting and the severity of nausea, as well as improved satisfaction during the $24 \mathrm{hr}$ period after thyroid surgery, compared to the control and sham groups.

Thyroid surgery is a surgery with a relatively higher PONV incidence of $60-84 \%$ [3]. The main cause of PONV after thyroid surgery is not entirely clear, but it is thought to result from the surgical procedure (surgical handling of neck structures), female sex, use of volatile anesthetics, non-smoking, postoperative opioid use, history of motion sickness or previous PONV history [13]. PONV could adversely affect patients who have received thyroid surgery, as vomiting can cause, or exacerbate, postoperative bleeding inside the surgery site. Therefore, it is reasonable that appropriate PONV prophylaxis should be considered as a

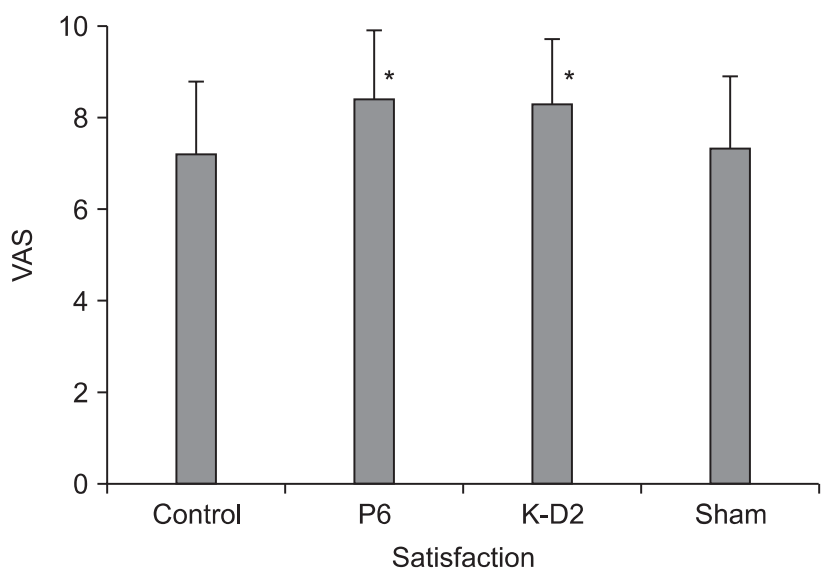

Fig. 4. Satisfaction scores (mean $\pm \mathrm{SD}$ ) at the $24 \mathrm{hr}$ postoperative period. VAS: visual analog scale. $* \mathrm{P}<0.05$ compared with the control and sham groups. P6 group: capsicum plaster at the P6 and an inactive tape at the deltoid region of both shoulders, K-D2 group: capsicum plaster at the K-D2 acupoint and an inactive tape at both deltoid regions, Control group: an inactive tape at the P6 acupoint and at both deltoid regions, Sham group: capsicum plaster on both shoulders and an inactive tape at both $\mathrm{P} 6$ points.

first course of action, rather than managing it after PONV has been established.

The Cochrane review from 2004 of 26 trials $(n=3347)$ documented that the effect of P6 acupoint stimulation is more prevalent in patients with risk of PONV with minimal side-effects [5]. Although the mechanisms of action of these techniques are still not well understood, low-frequency stimulation of skin sensory receptors may activate $A-\beta$ and A- $\delta$ fibers, which cause a release of endorphins from the hypothalamus and activate serotonergic and norepinephrinergic fibers [14]. Misra et al. [10] reported that a continuous low-intensity stimulation of the P6 acupoint with capsicum plaster is an effective method for the prevention of PONV after middle ear surgery, and its efficacy is comparable to ondansetron for the first six hours after surgery. Capsaicin also has a direct action on the vagal modulation and cause gastric relaxation, thereby inhibiting PONV [8]. Our results showed that the capsicum plaster at the P6 or K-D2 acupoints during thyroid surgery provided a 35\% reduction in PONV. Our data suggest that capsicum plaster application at the K-D2 acupoint is similar in effectiveness to that at the $\mathrm{P} 6$ acupoint, as was proved in our previous report [8], but this data is more faith because including sham results. The incidence of the need for rescue antiemetic drugs in the treatment groups was significantly less frequent than in the control and sham groups $(\mathrm{P}<0.001)$, which was caused by a reduction of PONV. K-D2, the Korean hand acupuncture points in Koryo hand therapy, which was described by the Korean physician Yoo [15], is not identical to the Chinese acupuncture point P6. Koryo hand therapy has been used as the method of treatment in two million Koreans, although this 
method is rarely applied in Western medicine.

The use of capsicum plaster as an antiemetic treatment has many benefits. First, the cost of either acupressure (approximately \$8.00) [16] or a transcutaneous acupoint electrical device (ReliefBand $\left.{ }^{\circledR}\right)(\$ 30)$ [17] is expensive compared to capsicum plaster ( $\$ 1$ for 10 sheets). Second, capsicum plaster is noninvasive, simple, painless and easy to apply at the correct point compared to acupuncture. The size $\left(0.95 \mathrm{~cm}^{2}\right)$ of capsicum plaster is convenient, and it is available for $8-12 \mathrm{hr}$ because of the capsicum element [18]. Na et al. [6] reported the incidence of postoperative nausea was reduced by acupressure at the P6 acupoint from 39.1 to $16.7 \%$ in patients undergoing a thyroidectomy. However, this study did not include a sham-controlled procedure. Acupressure at the P6 acupoint has occasionally induced uncomfortable feeling, skin irritation, ongoing pain and a wrist edema [5].
Many acupuncturists consider De-Qi, a typical sensation of proper acupuncture needle position, to be crucial in achieving the effect of acupuncture [19]. De-Qi is usually not elicited when the capsicum plaster is applied to the acupoint. In this study, an experienced acupuncturist confirmed the correct placement of the capsicum plaster at the P6 and K-D2 acupoint and the placement site in the shoulder for the sham group.

PONV studies need sample sizes of at least 100 per group to be able to demonstrate antiemetic efficacy [20]. A limitation of our study is that the 46 patients per group is somewhat small to provide strong support for the conclusion, although this study has powered to detect a possible treatment effect.

In conclusion, the capsicum plaster at the P6 and K-D2 acupoints is a promising antiemetic method for the patients undergoing thyroid surgery.

\section{References}

1. Macario A, Weinger M, Camey S, Kim A. Which clinical anaesthesia outcomes are important to avoid? The perspective of patients. Anesth Analg 1999; 89: 652-8.

2. Kerger H, Turan A, Kredel M, Stuckert U, Alsip N, Gan TJ, et al. Patients' willingness to pay for antiemetic treatment. Acta Anaesthesiol Scand 2007; 51: 38-43.

3. Ewalenko P, Janny S, Dejonckheere M, Andry G, Wyns C. Antiemetic effect of subhypnotic doses of propofol after thyroidectomy. Br J Anaesth 1996; 77: 463-7.

4. Sonner JM, Hynson JM, Clark O, Katz JA. Nausea and vomiting following thyroid and parathyroid surgery. J Clin Anesth 1997; 9: 398-402.

5. Lee A, Fan LT. Stimulation of the wrist acupuncture point P6 for preventing postoperative nausea and vomiting. Cochrane Database Syst Rev 2009; 15: CD003281.

6. Na SH, Kim NY, Kil HK. The prophylactic effect of acupressure (P6) on the postoperative nausea and vomiting in patients underwent thyroidectomy. Korean J Anesthesiol 2009; 56: 413-8.

7. Schlager A, Boehler M, Pühringer F. Korean hand acupressure reduces postoperative vomiting in children after strabismus surgery. Br J Anaesth 2000; 85: 267-70.

8. Kim KS, Koo MS, Jeon JW, Park HS, Seung IS. Capsicum plaster at the Korean hand acupuncture point reduces postoperative nausea and vomiting after abdominal hysterectomy. Anesth Analg 2002; 95: 1103-7.

9. Frerick H, Keitel W, Kuhn U, Schmidt S, Bredehorst A, Kuhlmann M. Topical treatment of chronic low back pain with a capsicum plaster. Pain 2003; 106: 59-64.

10. Misra MN, Pullani AJ, Mohamed ZU. Prevention of PONV by acustimulation with capsicum plaster is comparable to ondansetron after middle ear surgery. Can J Anaesth 2005; 52: 485-9.

11. Kim KS, Kim KN, Hwang KG, Park CJ. Capsicum plaster at the Hegu point reduces postoperative analgesic requirement after orthognathic surgery. Anesth Analg 2009; 108: 992-6.

12. Dundee JW, Ghaly RG, Bill KM, Chestnutt WN, Fitzpatrick KT, Lynas AG. Effect of stimulation of the P6 antiemetic point on postoperative nausea and vomiting. Br J Anaesth 1989; 63: 612-8.

13. Joris JL, Poth NJ, Djamadar AM, Sessler DI, Hamoir EE, Defêchereux TR, et al. Supplemental oxygen does not reduce postoperative nausea and vomiting after thyroidectomy. Br J Anaesth 2003; 91: 857-61.

14. Stein DJ, Birnbach DJ, Danzer BI, Kuroda MM, Grunebaum A,Thys DM. Acupressure versus intravenous metoclopramide to prevent nausea and vomiting during spinal anesthesia for cesarean section. Anesth Analg 1997; 84: 342-5.

15. Yoo TW. Explanation of koryo sooji chim. 10th ed. Seoul, Eumyangmekjin Press. 2001, pp 170-81.

16. Fan CF, Tanhui E, Joshi S, Trivedi S, Hong Y, Shevde K. Acupressure treatment for prevention of postoperative nausea and vomiting. Anesth Analg 1997; 84: 821-5.

17. Zarate E, Mingus M, White PF, Chiu JW, Scuderi P, Loskota W, et al. The use of transcutaneous acupoint electrical stimulation for preventing nausea and vomiting after laparoscopic surgery. Anesth Analg 2001; 92: 629-35.

18. Nam S. Treatment of capsicum plaster. Seoul, Hanam Press. 2009, pp 201-15.

19. Vincent CA, Richardson PH, Black JJ, Pither CE. The significance of needle placement site in acupuncture. J Psychosom Res 1989; 33 : 489-96.

20. Apfel CC, Roewer N, Korttila K. How to study postoperative nausea and vomiting. Acta Anaesthesiol Scand 2002; 46: 921-8. 